\title{
PSYCHOTRIA INEGI, UNA ESPECIE NUEVA EN JALISCO (MÉXICO)
}

\author{
I. García GonzÁlez y A. Borhidi² \\ ${ }^{1}$ Instituto Nacional de Estadística y Geografía (INEGI) Aguascalientes, México \\ E-mail:irene.gonzalez@inegi.org.mx \\ ${ }^{2}$ Departamento de Fitotaxonomía y Geobotánica, Instituto de Biología, Universidad de Pécs \\ H-7624 Pécs, Ifjúság útja 6, Hungría; E-mail: borhidi@gamma.ttk.pte.hu
}

(Received 11 November, 2014; Accepted 15 December, 2014)

The new Psychotria species belongs to the panamensis-mexiae complex with its large long deciduous ferrugineous terminal stipules, but differs from them by having shorter inflorescence, 2-3 times larger flowers, smaller leaves and less numerous secondary nerves. It is of allopatric distribution being endemic to Jalisco state, while the area of $P$. mexiae Standl. extends from Veracruz to Costa Rica and the populations of $P$. panamensis Standl. are found from Veracruz to Colombia.

Key words: INEGI, Jalisco, Mexico, new, Psychotria, Rubiaceae

\section{Psychotria inegi I. García González et Borhidi, spec. nova, hoc loco} (Fig. 1)

Tipo: México, Jalisco, Mpio. Talpa de Allende, $4.5 \mathrm{~km}$ al SE de la localidad El Refugio. Bosque mesófilo con Acer, Juglans, Podocarpus y Pinus. Coord.: $20^{\circ} 12^{\prime} 59^{\prime \prime} \mathrm{N}, 104^{\circ} 45^{\prime} 23^{\prime \prime}$ W, alt. 1713 m snm. Col.: Victor Lazarin Soto, Guadalupe Mendoza Correa e Irene García González (128), 21.05.2012. Holotipo: INEGI, isotipo: MEXU.

Frutex 2.5-3 m altus, rami cylindracei, cinerascentes vel brunneo-rubelli, profunde striati, juveniliores cinerei et laeves, ramulis purpurascentes leviter compressi, cystolithibus abunde obsiti, glabri. Stipulae interpetiolares ranissime caducae cum anillo e colleteribus ferrugineis restante, terminales longi, cinerei vel plerumque cum aetate ferrugineae, glabrae, in vainam 25-30 mm longam et 3-5 mm latam connatae, lineares vel elongato-lanceolatae, tenues, apiculatae et acutae, apice saepe curvatae, finalmente caducae, ante caidam per hendiduram lateralem apertae, usque ad 7-8 mm latae. Folia lanceolata, oblanceolata vel anguste elliptica, 3.5-14 cm longa et 1-2.5 cm 
lata basi apiceque longe attenuata, apice acuta et mucronata saepe leviter falcata, basi longe cuneata, in petiolum 0-10 mm longum decurrentia, supra viridia et nitidula, subtus pallidiora, utrinque glabra; nervo medio supra prominulo, subtus prominente, lateralibus utroque latere 6-10 valde angustis, supra vix conspicuis, subtus tenuiter prominulis, scrobiculis minute pelosis in axillis nervorum lateralium, e nervo medio casi rectangulariter abeuntibus, apicem versus valde curvatis, ante marginem conjunctis, papyracea vel cum aetate chartacea, margine integra et plana. Inflorescentiae terminales o subterminales, solitariae, paniculatae breves, usque ad 6-7 cm longae et 3-4 cm latae, medium foliorum non vel vix superantes, essentialiter glabrae; bracteae absentes, bracteolae ramificationum paniculae ovatae vel lanceolatae, 1-1.5 mm longae, acutae membranosae et ferrugineae, caducae. Pedunculum 1-2 cm longum, rami laterales inferiores 2, in axe centrali ab corymbo-cymoso terminali usque ad $2.5 \mathrm{~cm}$ longe distantes, usque ad $1.5 \mathrm{~cm}$ longae arcuato-ascendentes, in 3 inflorescentiis cymosis 5-7-floris terminantes; flores sessiles; corymbus terminales dense ramosi, 5-rami. Flores albi. Hypanthium obovatum, glabrum, $1 \mathrm{~mm}$ altum, tubus calycis $1 \mathrm{~mm}$ longus, apice truncatus, 5 denticulis distantibus $0.1-0.2 \mathrm{~mm}$ longis vel obsoletes vel irregulariter dispositis, utrinque glabris. Corolla alba, 8-10 mm longa, tubus 5-7 mm longus, basi $2 \mathrm{~mm}$, fauce $3 \mathrm{~mm}$ latus, extus glaber, intus in zona insertionis staminorum hirsutus, lobi corollae 5, oblongo-triangulares vel ovati, 2-3 mm longi, apice acuti, apiculati et cucullati, utrinque glabri. Stamina 5, in tubum corollinum $2 \mathrm{~mm}$ sub fauce inserta, filamenta $2 \mathrm{~mm}$ longa, violacea vel nigra in sicco; antherae ellipticae, $1 \mathrm{~mm}$ longae, basi dorsifixae, inter lobos corollinos exsertae. Ovarium semiinferum, 2-3 mm longum, oblongo-obovatum, pars libera superior e tubo calycis elevata. Stylus $3 \mathrm{~mm}$ longus, in medio tubi corollini inclusus, apicem versus incrassatus, pulverulentus; stigma 0.3-0.5 mm longum, brevissime bilobatum. Fructus ignotus.

Arbusto de 2.5-3 m de alto; ramas cilíndricas, grisáceas, pardusco-rojizas, toscamente estriadas, las más jóvenes grisáceas y lisas, las ramitas rojizas, poco comprimidas y provistas de abundantes cistolitos, glabras. Estípulas interpeciolares caen muy temprano, dejando un anillo de coléteres ferruginosas, las terminales, largas, grisáceas o mayormente ferrugíneas, glabras, connadas en vaina de 25 a $30 \mathrm{~mm}$ de largo y 3 a $5 \mathrm{~mm}$ de ancho, lineares a oblongolanceoladas, estrechadas y apiculadas, a veces encorvadas en el ápice, caen más tarde; antes de caerse se abren con una hendidura lateral llegando a una anchura de hasta 7-8 mm. Hojas lanceoladas u oblanceoladas a estrechamente elípticas, de 3.5 a $14 \mathrm{~cm}$ de largo y 1 a $2.5 \mathrm{~cm}$ de ancho, largamente estrechadas en ambos extremos, agudas y mucronadas, a menudo ligeramente falcadas en el ápice, largamente estrechadas y cuneadas en la base, decurriendo en el pecíolo de 0 a $10 \mathrm{~mm}$ de largo, verdes y nitídulas en el haz, más claras y pálidas en el envés, glabras en ambas caras; nervio central promínulo en el haz, prominente en el envés, los laterales 6-10 pares muy angostos, apenas visibles 


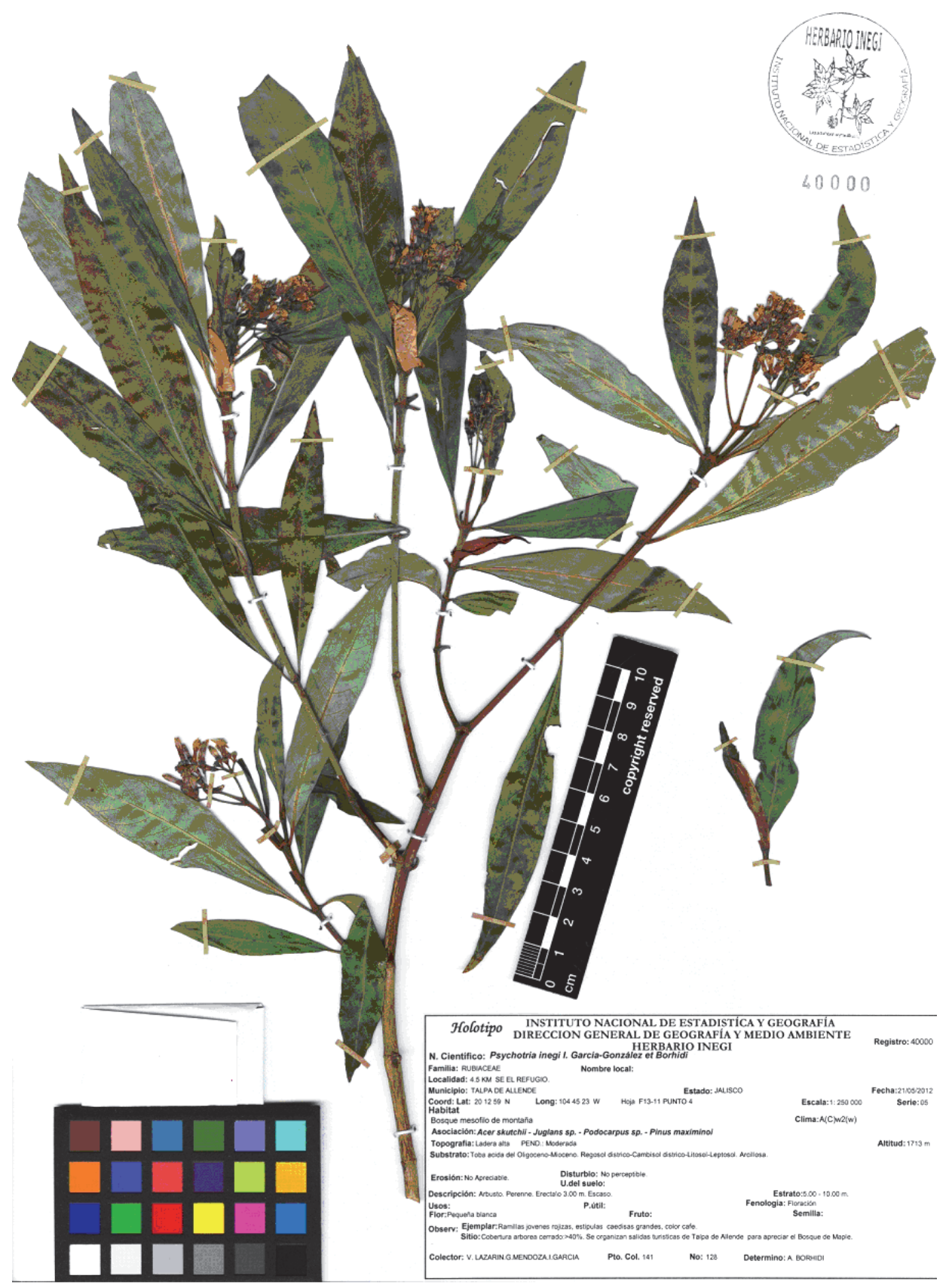

Fig. 1. Holotipo de Psychotria inegi I. García González et Borhidi en el Herbário del INEGI 
en el haz, tenuemente prominulos en el envés, con escrobículos menudamente pelosos en las axilas, salen casi rectangularmente del nervio central, luego encorvados hacia el ápice, anastomosandose antes del margen, papiráceas a cartáceas con la edad, el margen plano, entero. Inflorescencias solitarias, terminales o subterminales, paniculadas, cortas, llegando \pm hasta la mitad de las hojas, hasta 6 a $7 \mathrm{~cm}$ de largo y 3 a $4 \mathrm{~cm}$ de ancho, esencialmente glabras; brácteas ausentes, las bractéolas en las ramificaciones de la panícula, aovadas o lanceoladas de 1 a $1.5 \mathrm{~mm}$ de largo, agudas, membranosas, ferrugíneas, caedizas; pedúnculos de $1 \mathrm{a} 2 \mathrm{~cm}$ de largo, las 2 ramas laterales inferiores se alejan en el eje central en una distancia de hasta $2.5 \mathrm{~cm}$ de la parte cimosocorimbosa terminal; los ejes laterales de hasta $1.5 \mathrm{~cm}$ de largo, arqueadamente ascendentes, terminando en 3 inflorescencias parciales cimosas 5-7-flores, con flores sésiles, el corimbo terminal con 5 ejes densamente dispuestos. Flores blancas. Hipanto obovado, glabro de $1 \mathrm{~mm}$ alto, limbo del cáliz $1 \mathrm{~mm}$ de largo, truncado en el ápice, con 5 dentículos distantes de 0.1 a $0.2 \mathrm{~mm}$ de largo, o irregulares u obsoletos, glabro en ambas caras. Corola blanca, 8 a $10 \mathrm{~mm}$ de largo, tubo 5 a $7 \mathrm{~mm}$ de largo, $2 \mathrm{~mm}$ de ancho en la base, $3 \mathrm{~mm}$ en la garganta, glabro por fuera, con un anillo de pelos por dentro en la zona de inserción de los estambres, lóbulos corolinos oblongo triangulares u oblongo aovados, de 2 a $3 \mathrm{~mm}$ de largo, agudos, apiculados con forma de capucha en el ápice, glabros en ambas caras, reflejos durante la antesis. Estambres 5, insertos en el tubo $2 \mathrm{~mm}$ debajo de la garganta, filamentos de $2 \mathrm{~mm}$ de largo, pulverulentos, violáceos a negros en seco; anteras elípticas, de $1 \mathrm{~mm}$ de largo, dorsifijas en la base, exertos entre los lóbulos corolinos. Ovario semiínfero de 2 a $3 \mathrm{~mm}$ de largo, oblongo-obovado, la porción libre se eleva del tubo del cáliz. Estilo de $3 \mathrm{~mm}$ de largo, incluso en la mitad del tubo corolino, engordandose hacia arriba, pulverulento; estigma de 0.3 a $0.5 \mathrm{~mm}$ de largo, muy brevemente bilobado. Fruto desconocido.

Etimología: La especie lleva como epiteto específico Instituto Nacional de Estadística y Geografía, (INEGI), que organiza y realiza las expediciones científicas con el fin de conocer y registrar los recursos y riqueza naturales de México.

Especie próxima Psychotria mexiae Standl. que se distribuye desde Veracruz hacia al Sur hasta Costa Rica, que difiere en tener estípulas más cortas, hojas largamente acuminadas y apiculadas, con nervios laterales 10-13 pares, su inflorescencia con 4 ejes laterales en el nódulo inferior, flores pequeñas con tubo corolino de 2.5 a $4.5 \mathrm{~mm}$ largo, lóbulos corolinos de 1.5 a $2 \mathrm{~mm}$ de largo, estambres sésiles. La Psychotria panamensis Standl. difiere en tener estípulas (hasta $50 \mathrm{~mm}$ ), hojas (hasta $30 \mathrm{~cm}$ ) e inflorescencias (hasta $10 \mathrm{~cm}$ ) mucho más grandes, nervios secundarios 8-19 pares, flores a la mitad del tamaño, con tubo corolino de 2 a $3 \mathrm{~mm}$ de largo. 
Agradecimientos - Los autores desean expresar agradecimiento a los especialistas de Uso del Suelo y Botánica, porque gracias a su valioso esfuerzo durante las exploraciones de campo para la actualización de la Cartografía de Uso del Suelo, se han encontrado especies interesantes, y al Dr. Gerardo Adolfo Salazar, jefe del Departamento de Botánica, del Instituto de Biologia de la UNAM y al Dr. David Sebastian Gernandt, jefe del Herbario Nacional de México (MEXU) por su apoyo en crear condiciones favorables para este trabajo. Los estudios fueron apoyados por el INEGI y el Fondo Científico Nacional de Hungría (OTKA K68538).

\section{LITERATURA CONSULTADA}

Borhidi, A. (2012): Rubiáceas de México. Segunda y ampliada edición. - Akadémiai Kiadó, Budapest, 610 pp.

Taylor, C. M. (2012): Psychotria L. - In: Davidse, G., Sousa, M., Knapp, S. y Chiang, F. (eds gen.): Flora Mesoamérica. IV(2): Rubiaceae, Cordiaceae, Boraginaceae, Lamiaceae. Universidad Nacional Autónoma de México, Missouri Botanical Garden, The Natural History Museum (London), pp. 192-241. 